\title{
Electronic collection management and electronic information services
}

\author{
Gladys Cotter, Bonnie Carroll, Gail Hodge and Andrea Japzon
}

\section{Introduction}

One of the earliest significant implementations of electronic information management for libraries and information centers began in the 1960s and 1970s with dialup access to remote electronic databases such as those provided by Dialog and LexisNexis. The Internet has further contributed to the success of remote information systems and databases by increasing the information transfer rates from 300 baud to multiple megabits. The World Wide Web simplifies the process and interpretation of the bits that are transferred.

With these increased technical capabilities, new online databases that provide bibliographic and full-text access to information resources have proliferated and the volume of electronic information content now available from the desktop is staggering [28] - and it was recognized twenty years ago that the volume of information was already beyond our ability to absorb the increase [9]. Library catalogs have been computerized ${ }^{1}$ and are available and interoperable across the Internet. Audio, video, and multimedia resources are available, as are interactive services from games to banking. Filtering and push/pull delivery services help us manage information proliferation.

Electronic collection management and electronic information services are being pushed by the dramatic increase in the amount of digital information from an increasing variety of sources, by the new technologies in the information field, and by heightened user expectations. This paper explores some of the theoretical and practical aspects of collection management in the digital age. It also looks at the major trends in electronic user services including electronic information delivery and electronic reference. Finally, we address the challenges in user and personnel education in response to this changing environment and the increasingly information literate user population.

The electronic library and collection management in that library are relatively new concepts. The earliest literature dates to the 1970s and 1980s [10,14]. In 1984 Dowlin [10, p. 33] suggested that the electronic library has four attributes: (1) "management of resources with a computer", (2) "the ability to link the information provider with the information seeker via electronic channels", (3) "the ability for staff to intervene in the electronic transaction when requested by the information seeker", and (4) "the ability to store, organize, and transmit information to the information seeker via electronic channels". An electronic library utilizes both electronic information resources and electronic means to manage and move those resources.

There are sound reasons to consider collection management in an electronic environment. Libraries bring more than organization and intermediation to information collections. They also bring authority. Inclusion in a collection implies pertinence and appropriateness. At the same time, the same information "content" can and will be provided in different “containers”.

\section{Selection of information for electronic collections}

The number, scope, and type of information resources in electronic and print format, as Lyman and Varian [28] make clear, are overwhelming. There are many sources from which information can be drawn, and there continues to be a need to effectively evaluate those resources. Libraries have long functioned as one of the chief

\footnotetext{
1 Michael Buckland [7, Ch. 5]) makes the very useful distinction between electronic libraries and automated libraries. Electronic libraries contain electronically stored documents. Automated libraries (which may or may not be also electronic libraries) use automated search and retrieval systems, for example, online public access catalogs (OPACs).
} 
mechanisms for evaluation of information quality and relevancy.

If we take to heart Birdsall's [5] conception of "library" as process or service rather than "place", libraries must put added focus on how to manage collections. Electronic collection development must be consistent with the mission and an overall collection development plan. At the same time, collection development plans should take into account the electronic resources now available to libraries [12]. As it becomes easier or more efficient to move electronic and physical objects from a collection repository to the end user, the logic of maintaining redundant collections declines. Through selective collection policies, scarce resources can be used to broaden collections rather than to duplicate them. In Lee's [26] Electronic Collection Development: A Practical Guide, he discusses the application of print selection techniques to electronic media. Evaluation criteria specific to electronic tools are well-covered including interface usability, remote authentication, and archiving.

There are a number of online aids to assist librarians in collection development for either electronic or "traditional" materials. Librarians have discovered that the online booksellers like Amazon provide a vehicle for useful reviews and for purchasing.

With quality and permanence caveats in mind, the Web can be a source for collection development (see [25]). Web material should be subjected to the same scrutiny that any other resource should be subjected to and more so. There are a number of guides on evaluation of Web resources. Ciolek [8] and Tillman [39] have produced excellent Web resource guidance. Stability or permanence is cited as one key criterion for collection selection. There is growing evidence that Web site and page stability can be predicted with some degree of probability $[3,24]$.

Web resources, such as e-journals, increasingly meet quality and stability tests. University and government based Web sites provide extensive information. Many government agencies are migrating publicly accessible documents from paper to electronic format. As these trends increase libraries will have to consider these Web resources as appropriate for collection.

The Web may also serve as a viable substitute for expensive online databases and some traditional collections. Lewis-Somers [27] has found that there are a number of legitimate high quality free online resources that can be used in place of Westlaw or Lexis for legal research. Indeed, one can draw on Thomas and a multiplicity of other government e-publications and services to meet niche requirements.

The Web is sometimes seen as a "free" resource that can be "incorporated" into library collections without regard to collection objectives. In some sense, the Web is a free resource, but the process of evaluation, incorporation, and maintenance of Web resources in a collection is complex and expensive.

Finally, Keller [22] makes the very important observation that despite the metadata and sophisticated access systems, access is for the most part a question of "to what" rather than "how". Libraries must maintain good, current, and appropriate collections - however constructed - to meet the needs of their users. In order to maintain those collections, Johnson [20] argues persuasively for formal electronic collection policies that reflect the changing landscape and that provide information workers with the guidance and a decision framework. As we have seen, in an Internet world, the need to discover and select quality relevant materials is as important as in the "print” world but it is as yet very difficult to do. Guidelines, such as those provided by Tillman [39] or Ciolek [8] are critical and should be employed with rigor. 
In a paper-based world, the intellectual property had a physical form and, therefore, only one person could possess or use it at a time. Acquisition was the purchase of a commodity. Certainly, with the advent of photocopying machines, issues arose on the premise of one copy, one possession. To deal with this, copyright has traditionally been balanced by the fair use doctrine.

Because of the economic implications for these intellectual property issues in the digital environment, in recent years, information suppliers have begun to move away from the sale of information to the licensing of information. The digital revolution has significantly changed the ways in which information can be packaged. It need no longer be offered within "physical packages". It can now be transmitted from producer to publisher to end user electronically. That may well render the principle of first sale moot because information containers need not be used. It also means that limits are placed on the ability of the licensee to transfer or transmit information to third parties. Under most licenses, lending practices and in some cases universal access is either prohibited or restricted.

With this background in mind, organizations may follow an ownership or an access path. Whichever they choose, they must develop acquisitions policies. Acquisitions of electronic or digital materials often entail a set of decisions that differ somewhat from paper [31]. Some of these decisions entail organizational questions. Are electronic acquisitions treated as an intrinsic part of the library collection or are they categorized as "other resources”?

As Pinfield has shown [31], electronic acquisitions are not without their costs. These costs include the cost of the document (usually in the form of a license). These services are offered using a variety of pricing models individual subscriptions, bundled subscriptions, joint print and e-journal subscriptions, maximum number of users, and so on. The negotiations between library purchaser and licensor vendor can be time-consuming and complex.

\subsection{Access agreements}

Now that acquisitions have taken the form of licenses rather than purchases, there are critical differences between traditional and electronic access agreements. Licenses represent permission or authorization for one party to use the property of another under a prescribed set of conditions. These licenses may limit the number of users for a database at any given time, they may limit the range of authorized users, and they place a temporal limit on access. Typically, full text providers, particularly e-book databases, place a limit on the number of users at any given time. This is analogous, they argue, to the traditional model. There can be only as many users of a print book as there are copies of the book at any given time. Harris [13, p. 100] also makes important distinctions between the sale, the assignment, and the licensing of rights. An assignment of rights, unlike a sale of rights, is the non-exclusive permanent transfer of rights of access to the item under consideration. Licenses are less permanent and are analogous to renting rather than buying the object. A license or an assignment may specify the conditions under which copyrighted material may or may not be used.

Many national and international associations have developed guidance to help information managers negotiate licenses or to better understand their implications for libraries and other users (for example, the American Library Association, the American Association of Law Libraries, the Association of Re-search Libraries, the Australian Library and Information Association, the Canadian Library Association, the Colegio de Bibliotecarios de Chile, the European Bureau of Library, Information and Documentation Associations, to list a few). These concerns have sometimes resulted in a number of very specific agreements, as for example the International Federation of Reproduction Rights Organizations (IFRRO) - International Group of Scientific, Technical and Medical Publishers (STM) joint statements related to electronic storage [18] and digitization [19]. Harris [13] has prepared a guide to digital licensing under the American Library Association imprint. Her book provides a series of 
checklists and commentary. For example, she advises her readers to avoid verbal agreements in favor of the written; in part, because of the potential for future misunderstanding [13, xv]. Special issues arise when negotiating licenses for library consortia, so the International Coalition of Library Consortia (ICOLC) provides special guidance in this area [16].

Many professional organizations, such as the Association of Research Libraries (http://www.arl.org/ scomm/licensing/), the International Coalition of Library Consortia [16] and the International Federation of Library Associations and Institutions Licensing Principles [17], provide guidance on access, digital content, copyright and related issues. Symposia and other training events offered on digital copyright and associated issues include the International Summer School on the Digital Library in the Netherlands (http://www.ticer.nl/index.htm) sponsored by the Tilburg International Center for Electronic Resources at Tilburg University and the Libraries in the Digital Age Conferences held annually in Dubrovnik, Croatia (http://www.ffos.hr/lida/).

\section{Electronic information services}

As noted above, the management of electronic collections increasingly involves resources made available on the Web, but the Web is a complex information medium. It is both a repository for information and a transmission vehicle. It provides free public access and increasingly fee-based access to an immense body of digital material. It can provide the interface for both internally and externally hosted information, creating a seamless user environment. The Web also supports a wide range of interactive services including banking and securities trading. E-commerce has moved into many other areas and it is now possible to purchase a wide variety of goods and services online. Over the last several years, countries such as the United Kingdom, Canada, Australia, the United States and Lithuania are using the Web to disseminate information and to provide online services from government to citizen, government to government and between agencies of the government.

Electronic information services create a new set of demands for information providers. These services include new reference models, new means for information discovery and delivery, and demands for user and personnel education in the uses of the new resources and technologies. It has also prompted a re-examination of the rights and responsibilities of information providers, intermediaries, and end users [2].

A number of services are now offered online that, heretofore, were provided in person or through other print means. Online includes electronic reference and electronic document delivery systems. These services have been expanded to include automated information delivery and are built according to various interoperable standards. Electronic information services that have been created include interactive e-commerce and e-governance services as well as various organizational database management needs (including registrations, membership renewals) and other functions.

Advancements in electronic information services have also prompted new interest in artificial intelligence systems or agents to facilitate the delivery of information services, ranging from natural language processing to the creation of content [6]. These are future directions for information services and are only mentioned here. 


\subsection{Electronic reference}

Electronic reference has come to mean several different things. By one definition, electronic reference is interpersonal reference information management using electronic means for the patron query and for the reference response. Libraries have employed this model using telephones for years. E-mail, instant messaging and chat have added a new dimension to the reference relationship. In this form there is still a one-to-one patron to librarian exchange.

An Association of Research Library (ARL) survey found that in the ten years from 1991 to 2001, the median number of reference questions asked at reference desks dropped by nearly 30,000 [35]. Research libraries responded to this phenomenon by locating a librarian at the point of interaction between their users and their online resources by implementing chat also called digital, real-time or live reference services. Libraries have formed partnerships to provide 24/7 access to chat reference service for their users. The Boston Library Consortium Ask 24/7 (http://library.brandeis.edu/247/) and Maryland Ask Us Now (http://www.askusnow.info/) are examples.

Chat Reference: A Guide to Live Virtual Reference Services [34] and the ARL Chat Reference Spec Kit [35] are both useful guides designed to aid librarians in the implementation of this service. The sources provide information on selecting software, training staff, and evaluating the service. An executive summary of the Spec Kit can be found at http://www.arl.org/spec/273sum.html.

Policies and best practices for providing digital services are provided by QuestionPoint, an email reference system developed by the Library of Congress and OCLC [32]. QuestionPoint recently partnered with 24/7, a chat service to provide a complete venue for providing virtual intermediation. 24/7 provides guidelines for chat interactions and collaborative models for 24 hour staffing [33].

Libraries are currently conducting studies to evaluate and assess the effectiveness of the chat reference in answering reference questions. In a pilot study conducted by the University of Maryland, the researchers found that librarians answered questions with a high level of accuracy but when it came to escalating a question to proceed deeper into the research process with the questioner, on the whole, librarians were less than adequate in this regard. The finding suggests that the interactive aspects of chat reference need to be further developed [40].

Table 1

Examples of electronic reference desks

\begin{tabular}{|c|c|c|}
\hline Reference service title & Location & URL \\
\hline The Virtual Reference Desk & Wageningen UR Library & http://library.wur.nl/desktop/vrd/ \\
\hline Online Reference Resources & Sourasky Central Library & http://www.tau_ac.il/cenlib/eng/eResources/onlineRef.shtml \\
\hline Electronic Reference Shelf & McGill University & http://www.library.mcgill.ca/refshelf/swsindex.htm \\
\hline The Online Library & University of London & http://www.external.ull.ac.uk/ref.asp \\
\hline $\begin{array}{l}\text { Oxford Reference Online } \\
\text { (fee-based subscription) }\end{array}$ & Oxford University Press & http://www.oxfordreference.com \\
\hline \multirow[t]{3}{*}{ Ready Reference Shelf } & University of Michigan & http://www.lib.umich.edu/refshelf/ \\
\hline & NASA Goddard Space & http://library.gsfe.nasa.gov/vrs/vrs.htm \\
\hline & Flight Center Library & \\
\hline
\end{tabular}

A second model for e-reference has been developed and is more impersonal. Often, through email or Web-based queries, patrons place reference questions to anonymous reference librarians. The Internet Public Library provides an "Ask A Question" box with a pledge to respond within three days (http://www.ipl.org/div/askus/). The British "Ask-A-Librarian" service (http://www.ask-a-librarian.org.uk/) incorporates local reference librarians in an online service, with a pledge to respond within two working days. The Virtual Reference Desk (http://www.vrd.org) infrastructure developed by the Information Institute of Syracuse University and a network of partners provides 
software that triages reference questions through a series of experts who are linked by the network. Participating sites can be found through the AskA+ Locator which is organized by subject.

The National Information Standards Organization (NISO) in the U.S. recently released a draft standard, the Question \& Answer Transaction Protocol [30]. The protocol defines a method and structure for exchanging data between digital reference services. The draft standard is available for trial use by implementers until April 2005 when it will be made available for comment as a draft NISO standard.

A third model establishes a reference-like interface, the "electronic reference desk". Libraries provide information portals with selected useful online information finding tools. Examples are given in Table 1.

Libraries have also begun to place online pathfinders on their Web sites. Pathfinders are pre-prepared reference tools designed to point users to resources for commonly asked reference questions. These pathfinders may focus on locally held resources or they may take advantage of Web-based resources. For an example of a set of pathfinders, see the Internet Public Library pathfinder page at: http://www.ipl.org/div/pf/. Building pathfinders requires some html knowledge, excellent reference skills, and a grounding in Web evaluation techniques.

FAQs (frequently asked questions) are a variant on pathfinders and "ready reference" that have developed in the Web environment. FAQs, as the name implies, are lists of questions and answers to those questions client, patrons, browsers, and others have asked of the Web site creator. They provide a ready resource to many questions that might be asked and save time for all parties.

Increasingly e-reference has begun to blend these techniques together. A true reference site may combine pre-set access to a Reference Shelf, access to specific librarians via e-mail, and a network of additional experts that provide support for more detailed or tertiary questions. FAQs and pathfinders may also be provided, and they may be built automatically as a result of collecting the answers to previously asked e-reference questions. An example is the Virtual Reference Desk at Wageningen UR Library (http://library.wur.nl/desktop/vrd/) which includes an extensive reference shelf, a search engine, and an e-mail connection to a librarian. Additionally, many librarians are using the transcripts from chat and email sessions to create searchable knowledge bases that capture the knowledge of librarians. The New York Public Library’s “Ask A Question” service (http://ask.nypl.org/) includes chat reference in both English and Spanish, email reference, access to telephone reference, and a Q \& A archive, a searchable knowledge base.

\subsection{Information discovery}

The Web was once perceived not only as a supplement for libraries but as a replacement for them. Perhaps Louise Addis is the first information professional to appreciate the opportunities the Web can offer as a transfer medium [4, p. 45] to support a variety of disciplines and library needs [15]. It has been fairly well demonstrated that the Web is neither a library nor a substitute for libraries [23]. It is one of many resources in the information environment.

Therefore, one of the most critical issues for electronic collection managers is the heterogeneous nature of information resources and the proliferation of information discovery tools. While some portion of the Web content is indexed by Google, Yahoo! and other Web search engines, these search engines do not normally provide access to the "deep or hidden Web", that part of the Web that is hidden in databases, is password protected or behind firewalls. In addition, many different discovery mechanisms exist when trying to integrate external resources with internal databases, Web pages or documents in document management systems. New metasearch tools, also known as federated, broadcast, and cross-database search tools, are being deployed to allow these disparate, heterogeneous resources to be searched simultaneously and then displayed from their native systems in a single interface. Examples include the Google Appliance, Goldfire, WebFeat, Vivisimo, ExplorIt from Deep Web Technologies and portal products such as Autonomy. A listing of metasearch and metacrawler engines is available from Search Engine Watch (http://searchenginewatch.com/links/article.php/2156241\#reviews) along with links to 
related articles.

The metasearch or federated search tools are still being perfected with much debate surrounding their use. Encouragingly, as the federated search tools have evolved, services such as authentication, merging and duplicate identification have been added. However, problems still remain regarding relevancy, institutional repositories, and the one-size-fits-all philosophy that is behind metasearching. The ability for a cross-database search tool to return results from several sources is possible but relevancy ranking the items that are returned is difficult. Complications arise when library catalogs (MARC records) or sources that use OpenURL-based systems to link to full text articles are used. Setting the algorithm for the de-duplication of records located in several databases so that duplicates are eliminated but items that are not really duplicates are included is a challenging task [38].

For institutional repositories to be included in a federated search process, libraries would have to harvest the metadata from the repositories and then make the harvested data a target, a database in metasearching, which could be searched by the metasearch tool [38]. The Open Archives Initiative (OAI) protocol for metadata harvesting (http://www.openarchives.org) was formed to encourage the creation of e-print repositories and to facilitate research information distribution. Several cross-database science and technology search tools have been established using the OAI protocol. Arc (http://arc.cs.odu.edu), a cross archive search service, is one such tool, and, as of September 1, 2003, it contained 6,475,000 records from 160 repositories [29]. For more information on metasearching of institutional repositories follow the three part series on open archives initiative service providers in Library High Tech News.

At this time, federated search engines serve some user groups better than others. Undergraduate stu-dents are well served by federated search tools as they are looking for general or introductory level information on a given topic. Graduate students and faculty need thorough coverage within a given discipline and need the advanced searching capabilities of the native subject database [38]. Further, database producers feel that federated searching loses the search efficiencies unique to their native databases. For example, when metasearching JSTOR, it is not possible to search within a discipline as it is intended in the native design leaving the search result not subject focused. Licenses with database providers may or may not allow for the inclusion of their databases in a federated search. When licenses are renewed, federated searching will certainly be addressed [21].

\subsection{Information delivery}

Libraries and other information providers are moving to augment or change traditional models by providing a wide array of electronic services. A well-known example is the library at Los Alamos National Laboratory. This library is helping to meet the information needs of LANL scientists and engineers with the "Library Without Walls" concept. The LANL LWW provides services to its patrons at all times using electronic information delivery, enhanced database access, and customized linking between bibliographic and full text resources. It also provides electronic information dissemination through a "MyLibrary" service to its patrons.

Selective Dissemination of Information (SDI) and document delivery systems are of long standing in the library community. Document delivery is a library-managed courier service to move requested documents from the repository to the end user and back. Many libraries have long provided such services by moving physical objects. One of the largest such delivery services is the British Library's Document Supply Centre (BLDSC). In recent years, the BLDSC has moved toward extensive electronic document delivery by fax and through transmission of digital documents by ftp, telnet, e-mail attachment or the Web. Similarly, the services offered by such companies

as Amazon.com, Borders, or Barnes and Noble represent a form of document delivery provided by the commercial sector.

SDI represents a slight variation on the document delivery model. Under the SDI model, documents are delivered to end users based on some criteria other than specific demand for the object. This may be a user profile developed by the librarian in cooperation with the end user based on end user interests. Many vendors and some 
libraries suggest additional documents of potential interest to the end user by offering “more like these” services.

Electronic Information Delivery (EID) is a variation on SDI models that uses the growing power of Web technology and content-oriented standards to respond to user requests from distributed content sources. A number of digital EID systems have been developed based on eXtensible Markup Language (XML), the building of complex indexes, and filtering mechanisms [1]. XML is designed specifically to structure information so that user queries can get better content responses. It uses "HTML-like" syntax to provide application specific meaning to digital documents through character string mark up. A related technology is RSS (Rich Site Summaries), a series of XML-based formats for the syndication of news and news-like items. It allows "news aggregator" programs to monitor these feeds and to respond when changes or updates are identified. Libraries and other information aggregators can "capture" these feeds and present them in their own interface formats. The use of RSS and "news aggregators” is especially popular in the web blog community.

These SDI "push" technologies automatically provide end users with information based on predetermined interests. These interests may be established from a profile developed by interaction with the end user, or they may be developed based on the behaviors over time of the end user. News, weather bulletins, and stock quotes are common examples of information pushed or streamed to the desktops or pages of information consumers [11].

"Pull" or demand technologies require the user to be proactive. They require interaction at the trans-action time between the end user and the information provider. This is, in classic terms, the interaction between a reference librarian and a patron [36]. More recently, interactions between end users and search engines represent "pull" interaction because the end user is involved in the identification and "pulling" to himself or herself of the desired documents.

Most libraries that provide electronic resources offer some form of electronic pull. Clearly, the OPAC represents an interactive system for information discovery and retrieval. Some academic libraries offer electronic reserve services for their faculty and students. Reserve librarians place scanned or digitized documents in the service to be retrieved and viewed remotely by students on demand. Full text databases, like netLibrary, ingenta.com and OCLC's ArticleFirst may be used to pull documents either directly by the end user or through a librarian intermediary.

It is most interesting to note that the relationship between reference and information delivery is rapidly being redefined. Whereas information identification and then full text delivery used to be two distinct processes, as information is born and managed digitally, the identification of what a user needs is often only a click away from that information.

\section{User and personnel education}

User and personnel education in information resources and access have been traditional library functions from training in school and public libraries to orientation and bibliographic instruction at the university level. Because of the explosion in digital and online resources, the increased availability of in-formation services, and the frequent change in technologies and standards, library staff had to develop in-house training programs for users and staff. They have also brought pressure on library schools to enhance the skills of their graduates in these areas. In addition, the advent of the Web made easy access to information over the Internet a reality. With the advance of search engine technology, came a revolution in information literacy and information use. This brought new demands on information professionals as well as many new public policy issues such as the digital divide.

The digital divide and ways to democratize information and technologies were key issues in the discussions of the World Summit on the Information Society held in 2004. Initially sponsored by telecommunications companies to promote wider access to undeveloped markets, the social and educational component of this global forum quickly 
became apparent. The outcome includes statements regarding the need for education and access in order to reduce the digital divide as much as possible.

In many countries, academic and public libraries have been identified as key institutions to assist in bridging the digital divide. In order to address these issues, they must train and retrain staff in the use of electronic technology and familiarize their patron or client base in the use and scope of those technologies.

In the United Kingdom, The Peoples' Network is a government funded undertaking to bridge the digital divide (http://www.ukoln.ac.uk/services/lic/newlibrary/). Using lottery-derived funds passed through the New Opportunities Fund, the object of the project is to provide universal Internet access, digitize local resources, and teach online skills to the public. The program offers a useful checklist for personnel training and the areas that should be covered. To help implement the plan, public library staff are to be provided with an eight-point set of Information and Communications Technology (ICT) skills which include a grounding in the fundamentals of ICT, an understanding of how technologies can support library work, the health, safety and legal issues in the use of technologies, how to discover and retrieve digital items on behalf of users, using ICT to support reader development, using communications technologies to support users to ensure effective learning, ensuring effective management of ICT resources in libraries, and knowing how to use technology to improve their own efficiency. More advanced skills would include in-depth searching, web design, analysis of user needs, strategic planning, building partnerships with information providers and training staff and users to make more effective use of ICT.

Most libraries have patron training and education programs on "how to use the library". This may involve inlibrary training and tours and, sometimes, online tutorials. Most of these programs now include the use of electronic resources. Students consistently show poor quality selection ability when choosing Web materials. If Web documents are to be incorporated in library collections, it is incumbent on libraries to provide assessment as well as search/retrieval training to patrons as well as staff. Kathy Schrock's Guide for Educators on Critical Evaluation Information (http://school.discovery.com/ schrockguide/eval.html) provides survey forms and other information on teaching students of different ages to perform this critical evaluation.

\section{Conclusions}

Electronic collection management and electronic information services are in a period of rapid transition. Information organizations are undergoing redefinition. New forms of digital libraries and information collections are providing more information to more users more easily and on demand. These changes are being felt and responses are being made by information professionals throughout the world. The value of information is more appreciated than ever, but increasingly complex products require training for users and library personnel. Information collections are no longer geographically bound. Using Web access, it is possible to search the OPACs of many of the world's libraries and online resources from major primary and secondary publishers. Thus online and hybrid libraries have global reach. With global reach comes global responsibility.

The technology used to manage the information changes allows for extensive innovation in information selection, description, distribution, retrieval, and use. The new e-publishing environment requires new ways to assess information for the purpose of selection. There is a new array of information markup and cataloging systems for

collection management that, in turn, supports an equally growing array of information services for information producers, consumers, and intermediaries. The full story for electronic collection management and electronic information services has yet to be told. 


\section{References}

[1] M. Altinel and M. Franklin, Efficient filtering of XML documents for selective dissemination of information, in: VLDB 2000: Proceedings of the 26th International Conference on Very Large Data Bases, September 10-14, 2000, Cairo, Egypt, pp. 53-64. (Online.) Available: http://portal.acm.org/citation.cfm?id=671841 (13 May 2005).

[2] American Library Association, Access to electronic information, services, and networks: An interpretation of the Library Bill of Rights (adopted January 1996, amended January 2005). (Online.) Available: http://www.ala.org/alaorg/oif/ electacc.html (13 May 2005).

[3] J. Bar-Ilan and B.C. Peritz, The life span of a specific topic on the Web: The case of 'Informatics': a quantitative analysis, Scientometrics 46(3) (1999), 371-382.

[4] T. Berners-Lee, Weaving the Web: The Original Design and Ultimate Destiny of the World Wide Web by Its Inventor, Harper, New York, 1999.

[5] W. Birdsall, The Myth of the Electronic Library: Information Management and Social Change in America, Greenwood, Westport, CT, 1994.

[6] S. Bringsjord and D. Ferrucci, Artificial Intelligence and Literary Creativity: Inside the Mind of Brutus, a Storytelling Machine, Lawrence Erlbaum, Mahwah, NJ, 1999.

[7] M. Buckland, Redesigning library services: a manifesto (1997, orig. pub 1992). (Online.) Available: http://sunsite. berkeley.edu/Literature/Library/Redesigning/html.html (13 May 2005).

[8] T.M. Ciolek, The six quests for the electronic grail: Current approaches to information quality in WWW resources, Revue Informatique et Statistique dans les Sciences Humaines (1-4) (1996), 45-71. (Online.) Available: http://www.ciolek.com/ PAPERS/six-quests1996.html (13 May 2005).

[9] I. de Sola Pool, Tracking the flow of information, Science 221(4611) (1983), 609-613.

[10] K. Dowlin, The Electronic Library, Neal-Schuman, New York, 1984.

[11] J.I. Dysart and R.J. Jones, Tools for the future: Recreating or 'renovating' information services using new technologies, Computers in Libraries (1995 January), p. 16.

[12] K. Gessesse, Collection development and management in the twenty-first century with special reference to academic libraries: An overview, Library Management 21(7) (2000), 365-372.

[13] L.E. Harris, Licensing Digital Content, American Library Association, Chicago, 2002.

[14] S. Harter and K. Kister, Online encyclopedias: The potential, Library Journal 106(15) (1981).

[15] M. Henderson, FM Interview: Louise Addis, FirstMonday 5(5) (2000). (Online.) Available: shttp://www.firstmonday.dk/ issues/issue5_5/addis/ (13 May 2005).

[16] ICOLC, Statement of current perspective and preferred practices for the selection and purchase of electronic information. Update No. 1: New developments in e-journal licensing (2001). (Online.) Available: http://www.library.yale.edu/consortia/ 2001currentpractices.htm (13 May 2005).

[17] IFLA, Licensing principles (2001). (Online.) Available: http://www.ifla.org/V/ebpb/copy.htm (13 May 2005).

[18] IFRRO, Joint statement on electronic storage of STM material (1992). (Online.) Available: http://www.ifrro.org/papers/ stmjoint.html (13 May 2005).

[19] IFRRO, Joint statement on the digitisation of printed STM materials (1998). (Online.) Available: http://www.ifrro.org/ papers/stmjoint2.html (13 May 2005).

[20] P. Johnson, Collection development policies and electronic information policies, in: Collection Management for the 21st Century: A Handbook for Librarians, G.E. Gorman and Ruth Miller, eds, Greenwood, Westport, CT, 1997, pp. 83-104.

[21] JSTOR, Metasearching JSTOR, JSTORNEWS 18(1) (2004). (Online.) Available: http://www.jstor.org/news/2004.02/ metasearch.html (13 May 2005).

[22] M. Keller, Foreign acquisitions in North American research libraries, FOCUS on the Center for Research Libraries 12(4) (1992), special insert.

[23] W. Koehler, Digital libraries and World Wide Web sites and page persistence, Information Research 4(4) (1999). (Online.) Available: http://InformationR.net/ir/4-4/paper60.html (21 April 2004).

[24] W. Koehler, Web page change and persistence - A four-year longitudinal study, Journal of the American Society for Information Science and Technology 53(2) (2002), 162-171.

[25] S. Lee, Collection Development for the Electronic Environment, Haworth, Binghampton, NY, 2000.

[26] S. Lee, Electronic Collection Development: A Practical Guide, Neal Schuman, New York, 2002.

[27] S. Lewis-Somers, Electronic research beyond LEXIS-NEXIS and Westlaw: Lower cost alternatives, in: Teaching Legal Research and Providing Access To Electronic Resources, G. Hill, D. Sears and L. Lyman, eds, Haworth Press, New York, 2001.

[28] P. Lyman and H.R. Varian, How much information? (2003). (Online.) Available: http://www.sims.berkeley.edu/research/ projects/how-much-info/index.html (13 May 2005).

[29] G. McKiernan, E-Profile: Open archives initiative service providers. Part 1: Science and Technology, Library Hi Tech News 20(9) (2003), 30-38.

[30] NISO, Question/Answer Transaction Protocol (Draft, April 2004). (Online.) Available: http://www.niso.org/committees/ net-refprotocol.html (13 May 2005).

[31] S. Pinfield, Managing electronic library services: current issues in UK higher education institutions, Ariadne 29 (2001). (Online.) Available: http://www.ariadne.ac.uk/issue29/pinfield/ (13 May 2005).

[32] QuestionPoint User Group, Library of Congress QuestionPoint User Guidelines (2003). (Online.) Available: http://www. loc.gov/rr/digiref/QP_best_practices.pdf (13 May 2005).

[33] QuestionPoint, 24/7 reference collaborative policies and procedures (2005). (Online.) Available: http://www. questionpoint.org/ordering/cooperative_guidelines_247rev3.htm (13 May 2005). 
[34] J. Ronan, Chat Reference: A Guide to Live Virtual Reference Services, Greenwood, Westport, CT, 2003.

[35] J. Ronan and C. Turner, SPEC Kit 273, Chat Reference, The Association of Research Libraries, Washington, DC, 2003.

[36] D. Small Helfer, Not your traditional librarian anymore!, Searcher (May 1997) p. 66+.

[37] R. Tennant, Science portals, Library Journal 128(5) (2003), 34.

[38] R. Tennant, The right solution: Federated search tools, Library Journal 128(11) (2003b), 28-29.

[39] H. Tillman, Evaluating quality on the Net (2000). (Online.) Available: http://www.hopetillman.com/findqual.html (13 May 2005).

[40] M. White, E. Abels and N. Kaske, Evaluation of chat reference service quality, D-Lib Magazine (February 2003). (Online.) Available: http://www.dlib.org/dlib/february03/white/02white.html (13 May 2005). 